\title{
COMENTARIO EDITORIAL ¿Influencian las fuentes de financiamiento las conclusiones de los estudios?
}

Uno de los objetivos de Evidencia en atención primaria es ofrecerle a nuestros lectores un comentario acerca de la validez y aplicabilidad de los estudios más destacados de la atención primaria.

Esto se logra luego de aplicar estrictos criterios de análisis metodológico y cotejar las conclusiones con nuestra práctica.

Sin embargo existe un punto de creciente preocupación, destacado en publicaciones recientes, referente a la posible influencia de algunos intereses en las conclusiones alcanzadas en los diferentes estudios. Estos posibles conflictos de intereses se definen como un conjunto de condiciones por las cuales el juicio profesional con relación a un interés primario (como el bienestar de los pacientes o la validez de una investigación) tiende a ser excesivamente influenciada por un interés secundario (como una ganancia financiera).

La industria farmacéutica tiene un importante y constructivo rol en la medicina académica apoyando tanto la educación médica como la investigación, pero no son nuevas las controversias entre las relaciones financieras de médicos y de esta industria. Lo que no se sabe es en qué magnitud el financiamiento de la industria a investigaciones y educación médica influencia las opiniones y conductas de médicos e investigadores.

El método científico es riguroso y los datos avalan o no una determinada conclusión independientemente de la financiación; sin embargo, este argumento se debilita cada vez más a medida que se acumulan evidencias sobre la existencia de conflictos de intereses.

Estudios como el de Chren y Landefeld (1) demostraron que las demandas médicas para incluir ciertas drogas a vademecums hospitalarios se asociaba a relaciones entre médico y fabricantes. Otros demostraron que ciertos beneficios económicos hacían más probable que los médicos indiquen estudios, operaciones o internaciones (2).

Un ilustrativo ejemplo de este tema es el actual debate sobre la seguridad de los bloqueantes cálcicos, tanto por la magnitud de la controversia como por el enorme mercado que estas drogas representan.

Algunos meta-análisis (3)(4) y estudios caso-control (5) en pacientes con cardiopatía isquémica sugirieron la posible asociación entre el uso de bloqueantes cálcicos y un mayor riesgo de infarto de miocardio. Esto abrió un intenso debate médico y extramédico que puso en duda la objetividad de los trabajos para valorar la seguridad de las drogas.

Un artículo recientemente pubicado de Stelfox y colaboradores (6) brinda la posibilidad de examinar el efecto generado por los potenciales conflictos de intereses financieros. En éste, se revisó la literatura sobre bloqueantes cálcicos publicada de Marzo de 1995 a Septiembre de 1996 y se clasificaron los artículos en función de la posición adoptada como de apoyo, neutros o críticos con respecto a su uso. El $80 \%$ de los autores de dichos artículos completaron un cuestionario acerca de sus relaciones financieras (laborales o de consulta, participación en simposios o charlas y apoyo a educación o investigación en los últimos 5 años), tanto con los fabrican- tes de bloqueantes cálcicos como con los fabricantes de drogas competidoras en el manejo de angina e hipertensión (ßbloqueantes, inhibidores de la enzima convertidora de angiotensina, diuréticos y nitratos). El estudio examinó la asociación entre las conclusiones publicadas sobre la seguridad de los bloqueantes cálcicos y las relaciones financieras de los autores con las compañías farmacéuticas.

Los autores que apoyaban el uso de bloqueantes cálcicos tenían una probabilidad significativamente mayor que los autores neutros o críticos de tener algún tipo de vínculo con los fabricantes de bloqueantes cálcicos $(96 \%, 60 \%$ y $37 \%$, respectivamente $p<0.001)$. Esta fuerte asociación y el hecho de que sólo dos de los 70 artículos revisados exponían los potenciales conflictos de intereses de los autores señala la necesidad de que esta relación quede claramente expuesta en los estudios que examinan productos farmacéuticos.

Stelfox propone como mecanismo que los autores completen un cuestionario similar al usado en este estudio, que informe acerca de sus relaciones financieras con las compañías farmacéuticas.

Sin embargo, tal como responde Jay Meltzer ( 7 ) sería ingenuo pensar que esto es suficiente para eliminar las influencias por conflicto de intereses. En primer lugar porque el instrumento propuesto (cuestionario autoadministrado) obtiene una información confusa al no tener un análisis del tipo de apoyo, el monto involucrado ni el momento en que se recibió. Por otra parte, aunque el financiamiento de las compañías farmacéuticas a las investigaciones tuvo la correlación más fuerte con publicaciones que avalaban el uso de antagonistas cálcicos, esto también fue cierto para las drogas competidoras. Esta asociación es esperable ya que una gran mayoría de investigadores clínicos cuentan con esta fuente de financiamiento para sus estudios y sería injusto que, sólo por este motivo, se lo considere un conflicto de intereses de tal magnitud que pueda sesgar los resultados. Contrariamente, los autores de los estudios más críticos, en general epidemiólogos, tienen pocos lazos con las compañías farmacéuticas pero muchas veces obtienen la información producida por otros. Esto no implica, por otra parte, que no tengan sus propios conflictos de intereses (que no siempre son financieros).

Meltzer descalifica este instrumento por tautológico y reduccionista, y considera que el debate más importante, no contemplado, es extrafinanciero: discriminar que evidencias serán tenidas en cuenta. Por un lado los críticos de los bloqueantes cálcicos consideran a los ensayos randomizados, con resultados principales duros, como única evidencia admisible. Por el otro, los promotores de estos agentes, apoyandose en las limitaciones de estos ensayos, confían más en el juicio clínico y el razonamiento causal de los consensos de expertos. Particularmente pienso que, aunque las opiniones de expertos tienen un gran valor orientador para la práctica médica, la calidad de la evidencia\# que aportan es inferior aún a estudios de caso-control y sus recomendaciones deberían ser tomadas como provisorias hasta que puedan comprobarse con estudios bien diseñados. Aún cuando los autores expresen opiniones 
propias, independientes de sus relaciones financieras con la industria farmacéutica, es vital para la transparencia del debate que todos los intereses sean expuestos abiertamente. Quizás un caso paradigmático sea el de los efectos nocivos ocasionados por el tabaquismo pasivo. Este tema ha cobrado gran vigencia debido a las permanentes disputas, tanto en el plano judicial como científico, originadas por los fuertes intereses que rodean a esta cuestión.

Un reciente y cuidadoso estudio de Barnes y Bero(8) analiza porque las revisiones arriban a diferentes conclusiones.

No es desconocido que muchos médicos prefieren las revisiones, por sobre los artículos originales, al considerar que resumen el conocimiento científicamente aceptado al momento de su publicación. Lamentablemente las revisiones, que siempre deben ser evaluadas en cuanto a su calidad, también varían en sus conclusiones según la fuente de financiamiento o la filiación de los autores. El estudio intenta determinar si factores como la calidad de la revisión, tipo de revisores (pares o no), tipos de daños a la salud, año de publicación o la filiación de los autores con la industria tabacalera, influencian las conclusiones sobre el efecto del tabaquismo pasivo. El $37 \%$ de los estudios analizados concluía que el tabaquismo pasivo no era perjudicial para la salud; de éstos, el $74 \%$ fueron publicados por autores con filiación a la industria tabacalera, definida por haber recibido alguna vez fondos por parte de una compañía tabacalera o institución asociada, o haber participado de al menos dos simposios financiados por la industria del tabaco. La filiación a las tabacaleras fue la única variable que se asoció con la conclusión de que el tabaquismo pasivo no era perjudicial (odds ratio* 88.4 ; IC 95\% 16.4 a 476.5; p 0.001) y resistió además todos los análisis de sensibilidad \# efectuados.

Si bien este tipo de estudios no determina causalidad, la magnitud de esta asociación, La consistencia de hallazgos en diferentes publicaciones y los poderosos intereses que podrian explicarla, hace improbable pensar que estas asociaciones sean debidas al azar. Como en el estudio anterior, sólo una minoría de los articulos (23\%) exponía las fuentes de financiamiento de sus investigaciones.

Los lectores, entonces, deberian poder conocer las filiaciones de los autores para evaluar potenciales conflictos de intereses. Estos dos estudios, junto con sus predecesores, han contribuido a consolidar la idea de que los conflictos de intereses tienen impacto en las conclusiones de los trabajos publicados en las revistas médicas.

Es por todo ésto que la completa transparencia de estas relaciones es imprescindible para preservar la integridad y validez de los estudios de investigación clínica y mantener la confianza pública en sus resultados.

Los equipos editoriales deberían contar con toda la información necesaria para evaluar la existencia de conflictos de intereses sin que esto implique una restricción automática en la publicación de determinados artículos, ya que las revistas médicas correrían el riesgo de limitar seriamente el debate. Además, si esto ocurriera, podría correrse el riesgo de iniciar una caza de brujas indiscriminada en nombre de la defensa de los intereses académicos. Simplemente sería suficiente con exponer claramente la relación de los investigadores con las compañías para que cada reporte pueda ser evaluado a la luz de los inevitables intereses en juego de los autores.

La clave es la transparencia y uno de los puntos críticos será definir lo más precisamente posible la relación de los autores con las fuentes de financiación en términos de cantidad, calidad y temporalidad. Obviamente no es lo mismo recibir un bolígrafo y un calendario de un laboratorio que ser asesor del mismo.

El British Medical Journal (BMJ) dedica gran parte de su último número a este tema(5). La revista envía a los autores de los artículos un formulario en el que se define que se entiende por conflicto de intereses. Esta definición es amplia y va más allá de intereses financieros, incluyendo intereses personales, políticos, académicos y religiosos. La BMJ revela la fuente de financiamiento de los artículos originales y los conflictos de intereses que los autores hayan manifestado en cualquier tipo de artículo. Si los autores no la informan, la revista escribirá "no declarada", en lugar de "ninguna". Es posible que medidas como las adoptadas por la BMJ no sean suficientes para resolver este problema pero al menos parecen orientadas en la dirección correcta.

En coincidencia con esta posición es norma de nuestra revista incluir al menos la fuente de financiamiento en cada uno de los estudios publicados y destacar en el comentario posibles conflictos de intereses detectados, brindando al lector la mayor cantidad posible de elementos de juicio para una mejor interpretación.

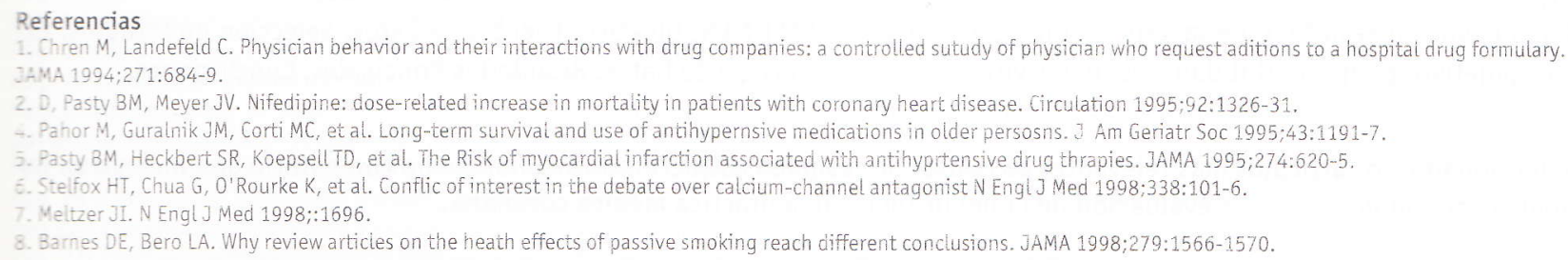

